\title{
APORTE SOCIAL DE MUJERES PUERTORRIQUEÑAS QUE UTILIZAN LA MEDICINA POPULAR COMO ALTERNATIVA DE SALUD PREVENTIVA Y CURATIVA
}

\section{Yolanda I. Díaz Pérez'}

\begin{abstract}
Las mujeres siempre hemos sido sanadoras de nosotras mismas y de (las) demás personas, y ahora reclamamos esa facultad como una parte del movimiento de espiritualidad femenino actual. La conexión de las antiguas parteras, brujas y videntes con las activistas sanitarias, curanderas, herbolarias, médium y expertas en el uso de cristales y gemas con fines curativos responde a una larguísima tradición de curación femenina.
\end{abstract}

Diana Stein

\section{Introducción}

\begin{abstract}
A 1 estudiar los orígenes de la medicina natural se constata el A papel central que ocupa la mujer como sanadora. Tan remoto como en las civilizaciones de Egipto y Sumeria se revela evidencia de su intervención a través de métodos que estimulan el poder dentro de la propia psiquis para sanar a las personas como individuos, a la comunidad y sanarse a sí mismas. Desde esta perspectiva, la mujer visualiza la salud y la sanación como realidades espirituales que guardan correspondencia con la ubicación apropiada de sí misma dentro del esquema total de lo existente. Lo anterior se da bajo

\footnotetext{
${ }^{1}$ Catedrática, Escuela Graduada de Trabajo Social Beatriz Lassalle, Universidad de Puerto Rico.
} 
la implicación del mantenimiento de la armonía y el balance con su propio ser interior, con su familia, con su comunidad, con el aspecto total del mundo natural y con el mundo de lo divino (Amenta y otras, 1995). Esta armonía, como puede desprenderse de la aseveración anterior, descansa sobre la noción de totalidad ( «wholeness»). Sobre esta base, cuando la mujer ejerce el papel de sanadora, aborda el estado de salud desde una óptica holística de la persona a quien asiste. Por eso no sólo presta atención a la queja principal que elabora dicha persona, sino que trata de conocer y ahondar en otros ángulos de su realidad. Así, le interesa saber quién es la persona, a qué se dedica, con quién(es) se interrelaciona. A su vez, el abordaje es integral, ya que considera las dimensiones o factores que pueden contribuir a la presencia o ausencia de enfermedad - la genética, dietética, ambiental, emocional, psicológica y espiritual.

Así pues, reconoce que asuntos tales como las crisis personales provocadas por la pérdida de personas queridas, las relaciones interpersonales que generan insatisfacción, eventos de impacto económico y otros, afectan adversamente el estado de salud. A su vez, para intervenir con la salud de una persona, la sanadora se sitúa a partir de las emociones o sentimientos de ésta, tales como su alegría, esperanza, valor, compasión y amor; como de su tristeza o dolor, desesperanza, coraje, miedo, resentimiento y odio, entre otros. En gran medida, la sanadora no sólo abarca la salud y la enfermedad, sino que trasciende al ámbito social, en su concepción más amplia.

\section{Definición del Problema y Justificación}

La utilización de la medicina natural como alternativa de salud ha sido una práctica a través de los siglos. No obstante la sofisticación científica y tecnológica de la medicina alopática, la medicina natural siempre ha mantenido su presencia.

A lo largo de los años desde la década del '70 hasta el presente, tanto en la experiencia práctica en servicio directo como en la adquirida en el campo de la educación en trabajo social, he encontrado evidencia empírica que demuestra el uso que se hace en la sociedad puertorriqueña de la medicina natural. Por el interés y estrecha relación con el campo de la salud tuve la oportunidad de conocer cómo las personas integran variaciones de la medicina natural a sus prácticas de salud. En su mayoría los casos encontrados eran de 
mujeres, de diversidad geográfica, cronológica, racial y socio-económica. No obstante, resulta pertinente indicar que debido a que la estrata socioeconómica que tiende a solicitar o ser referida a los servicios de trabajo social es la más baja, la mayoría de los casos encontrados correspondían a dicho nivel. Con respecto a la característica de la religión, en su mayoría eran católicas, o en sus prácticas de salud revelaron hacer referencia a muchos de los rituales de esa religión.

La ocurrencia repetida de este tipo de hallazgos de naturaleza empírica me llevó a plantearme la interrogante de cómo es la naturaleza de esta práctica de salud natural, en esencia popular. Me movió a explorar en detalle vertientes de dicha práctica y su tangencia con otras dimensiones, sobre todo la social.

Resultó significativo investigar la contribución social que han podido estar haciendo mujeres puertorriqueñas que han utilizado la medicina popular para prevenir o curar sus problemas de salud, los de sus familiares y los de otras personas en su comunidad. Fue pertinente explorar la biografía social de mujeres que han hecho uso de la medicina popular. A su vez, fue importante explorar el estado de salud de las mujeres, de los otros miembros de la familia y de otras personas de la comunidad. Por último, fue pertinente investigar qué han utilizado las mujeres para llevar a cabo su práctica de medicina popular y los usos específicos que le han asignado a lo que han utilizado.

El producto de la investigación que aquí presento puede resultar útil para las profesiones de ayuda, sobre todo las que atienden la esfera social, como es el caso del trabajo social. La salud representa un área vital para el funcionamiento individual y social del ser humano. Según Weil (1998) lo fundamental para gozar de salud es seguir una dieta adecuada, hacer ejercicio y disfrutar de paz mental. Define salud como un estado de balance:

\section{Es el balance entre el sistema de sanación del cuerpo y los estresores externos con los que nos enfrentamos (Weil, 1998:88).}

Por otro lado, define salud óptima como la fortaleza interior que permite a la persona estar en contacto con peligros o riesgos al organismo y no contraer enfermedad. «Es mucho más que la ausencia de enfermedad, es una sensación de fuerza y regocijo» (Weil, 1998:88). 
El uso de la medicina popular para promover estados físicos o emocionales particulares o para evitar, aliviar o curar distintas dolencias en la persona puede aportar a niveles óptimos de salud. Esto, a su vez, puede contribuir, individual o colectivamente a niveles más altos de productividad y eficiencia en el trabajo; a niveles más bajos de ausentismo, tanto de trabajadores como de estudiantes y a niveles más altos de entusiasmo, disposición y creatividad. Todas estas dimensiones son de particular pertinencia para la educación y la práctica del trabajo social. Por otro lado, el abordar el ámbito de la medicina popular en el Puerto Rico de hoy y adquirir conocimiento en esta área, le permite al trabajador o a la trabajadora social comprender mejor un aspecto de la realidad social puertorriqueña.

Fue de particular interés para la autora distinguir las prácticas de salud de cada mujer sin perder de vista las características sociodemográficas que la distinguen. La autora exploró de qué sectores geográficos proceden, a qué niveles socioeconómicos pertenecen y otras características que pueden orientar hacia investigaciones posteriores con una cantidad mayor de mujeres de la población, dirigidas hacia las posibles relaciones con determinadas variables.

\section{Revisión de Literatura}

La exploración de fuentes de referencia relacionadas con el problema de estudio incluyó una mirada al papel de las mujeres como sanadoras a través de la historia (Stein, 1992). Incluyó contenido crítico sobre la medicina alopática, esencialmente masculina y su contraparte, la curación femenina (Weil, 1998; Stein, 1992; Carlson, 1975). Incluyó, a su vez, un recuento histórico de cómo el ser humano ha tratado de encontrar en la naturaleza formas de sobrevivir (Rodríguez Malavé, 1999; Liogier, 1990). Finalmente exploró la curación femenina a través de las tres vertientes abordadas en el estudio: la de la yerbera, la partera y la santiguadora (Rodríguez Malavé, 1999; Stein, 1999; Maldonado, 1999; López Díaz, 1995).

\section{Marco Teórico}

Como se ha establecido en la discusión sobre la metodología cualitativa, ésta es la apropiada cuando impera bastante desconocimiento sobre las variables y la base teórica del área de estudio 
(Creswell 1994). Del estudio del proceso de las mujeres sanadoras, del significado que tienen para ellas sus experiencias y de la exploración a través del conversatorio y el contacto cara a cara se perseguía ir develando variables estrechamente vinculadas con el tópico del aporte social de la mujer a través de la medicina popular. De igual manera se aspiraba a ir identificando una base conceptual o teórica que fundamentara la búsqueda de referencia.

Los hallazgos y las conclusiones derivadas del estudio, y más adelante presentadas, apuntan hacia una serie de variables que han podido ser identificadas. Entre éstas: prácticas propiciatorias de estados satisfactorios u óptimos de salud; funciones de la vida cotidiana y prácticas de salud natural.

Con relación a la base conceptual o teoría que puede servir para fundamentar exploraciones posteriores sobre el tema se identifica la teoría feminista como fuerte anclaje de dicha gestión, sin que esto signifique la exclusión de marcos alternos de referencia.

\section{Propósito General y Propósitos Específicos}

\section{Propósito General del Estudio}

En el estudio abordé aspectos de las tres temáticas que en lo relacionado con mi trayectoria personal y profesional me interesan -el ámbito social, la salud y los asuntos de la mujer. Dicho interés me estimula a desarrollar compromiso y tratar de conocer a través del estudio y la acción directa cómo estas temáticas se concretizan en la sociedad puertorriqueña.

Por otro lado, mi gestión a través del estudio fue política en la medida en que persiguió contribuir a rescatar espacios que a la mujer le corresponden en justicia a su papel en la historia de la humanidad. Antes del patriarcado, imperante por los últimos cinco mil años, la mujer jugó un papel central como sanadora a través de prácticas naturales.

Si hoy la medicina es una profesión de hombres, las mujeres se ocuparon de sanar desde el principio... las mujeres [deben considerarse] a sí mismas creadoras activas del universo, de su propio ser y de su vida... Hasta que se estableció el orden patriarcal [lo anterior] formaba parte de la vida cotidiana, algo aceptado como lo es hoy el pronombre «él» 
en el lenguaje. Antes del patriarcado, la divinidad era una diosa, y en los matriarcados las mujeres no estaban excluidas; eran hijas de las mujeres y tenían su lugar respetado en la ley de la divinidad femenina, en la sociedad y en el orden del mundo natural (Stein, 1992:14-15).

A lo largo de la Edad Media la salud de las mujeres era asunto de mujeres. La comadrona era la única proveedora de servicios de salud a la mujer. Durante los siglos XVII y XVIII, la especialidad de las mujeres le fue siendo «tomada" por los hombres quienes se autodenominaron comadrones (Green, 1989).

En las postrimerías del siglo XX la mujer continuó luchando por la igualdad entre las personas en todas las esferas del quehacer social, económico y político. Está demostrando que el lugar que ocupó como recurso esencial y natural de la salud de los pueblos no tenía por qué perderlo. Perseguí mediante esta investigación explorar alternativas de salud natural mediante las cuales mujeres puertorriqueñas aportan al desarrollo social del pueblo.

Bajo el orden patriarcal se nos adoctrina a nosotras las mujeres a que velemos y nos preocupemos por todos los demás y, en última instancia, por nosotras mismas. Como añade Stein, somos las que parimos, las que criamos, las que enseñamos, las que alimentamos, las que apoyamos y las que valoramos a otros sin enseñarnos a alimentarnos, a apoyarnos y a valorarnos nosotras mismas. A las mujeres se nos enseña a ocultar nuestros cuerpos, se nos lascera seriamente la autoestima viéndonos como objetos sexuales y aparatos reproductores (Stein, 1992).

Por su parte Northrup (1994) también indica que el problema de cada mujer comienza por el solo hecho de su naturaleza de mujer en esta cultura. Esta nos programa a anteponer las necesidades de otros antes que las nuestras, por eso debemos hacer cambios radicales en nuestras mentes y en nuestras vidas para estar y mantenernos saludables. Es necesario un cambio de enfoque de lo que puede estar mal hacia lo que puede estar bien. Es imprescindible que la mujer adquiera poder (se apodere) para efectuar el cambio de las conductas destructivas hacia las que se asocian con la salud.

\section{Propósitos Específicos}

El estudio se guió por los siguientes propósitos específicos: 
- Investigar la contribución social que pueden estar haciendo mujeres puertorriqueñas que utilizan la medicina popular para prevenir o curar sus problemas de salud, los de sus familiares y los de otras personas en su comunidad.

- Explorar la biografía social de mujeres que hacen uso de la medicina popular.

- Explorar el estado de salud de las mujeres que hacen uso de la medicina popular, el de los miembros de su familia y el de otras personas en su comunidad.

- Investigar qué utilizan las mujeres que practican la medicina popular para llevar a cabo su quehacer y qué usos específicos le asignan a lo que utilizan.

\section{Preguntas de Investigación}

En la investigación se formularon las siguientes preguntas:

1. ¿Qué contribución social hacen las mujeres que utilizan la medicina popular para prevenir o curar problemas de salud?

2. ¿Cuál es la biografía social de las mujeres que hacen uso de la medicina popular?

3. ¿Qué estado de salud poseen las mujeres que utilizan la medicina popular, los miembros de su familia y los de su comunidad?

4. ¿Qué utilizan las mujeres que practican la medicina popular para llevar a cabo su quehacer y qué usos específicos le dan a lo que utilizan?

\section{Diseño Metodológico}

\section{Tipo de Diseño}

Las mujeres que utilizan la medicina popular y que aportaron testimonios sobre su práctica permitieron nuestro acceso al mundo 
de la prevención y la curación de males físicos y emocionales a través del uso de plantas medicinales, la partería y el santiguo. Cada una de las mujeres sujetos del estudio nos brindó la oportunidad de conocer, descubrir y comprender minuciosamente el significado de la cotidianidad de su oficio de yerbera, partera o santiguadora. Como en todo estudio fenomenológico, la metodología exigió un procedimiento mediante el cual se estudiaron los testimonios de un grupo pequeño de mujeres-sujetos con el objetivo de desarrollar patrones y relaciones con significado. Algunas de las sujetos fueron abordadas sobre la temática en más de una ocasión, lo cual contribuyó hacia la identificación de patrones y hacia el establecimiento de relaciones al interior de los datos.

El poder llevar a cabo este estudio, utilizando una metodología cualitativa, de tipo fenomenológico, significó mucho para mí desde el punto de vista de la integración de mi desarrollo como persona y profesional. A lo largo de mi vida he ido encaminándome más y más hacia un estilo de vida en comunión con la naturaleza. En lo personal he buscado acercarme cada vez más a los orígenes, a lo verdaderamente esencial. Como parte de dicha búsqueda surgió el rescatar la sabiduría de la medicina popular que desde niña conocía a través de mi madre y otras mujeres de la ruralía y el casco del pueblo de Cidra, donde me crié.

En relación con mi desarrollo profesional, el haber dedicado más de 20 años a la formación de profesionales en el campo del trabajo social ha sido fuente de motivación para explorar conocimientos y métodos de intervención lo más cónsonos posibles con las bases filosóficas de la profesión. Al adentrarme en el estudio de la metodología cualitativa, como parte de mi búsqueda como docente de cursos de investigación, me percaté de la congruencia de esta metodología con lo que yo entiendo debe ser esencial al trabajo social. Me refiero a las características de subjetividad, cercanía con el sujeto, concepto de lo único, autodeterminación local y solidaridad y acción que distinguen a la investigación cualitativa y que dignifican al trabajo social, cuando las acoge como suyas. Para el trabajo social como para la investigación cualitativa la realidad no es dada, el mundo social se construye humana y colectivamente dentro de un contexto histórico (subjetividad). El trabajo social al igual que la investigación cualitativa persigue mantener una relación empática con los sujetos, establecer intercambios interpersonales y relacionarse (cercanía con el sujeto). Para el trabajo social 
como para la metodología cualitativa es importante que los individuos y grupos puedan controlar su realidad (concepto de lo único). Tanto para el trabajo social como para la metodología cualitativa, el proceso y el producto deben estar en manos de los sujetos-participantes (autodeterminación local). Y por último, para el trabajo social como para la metodología cualitativa la prioridad deben ser los no poderosos, los sin poder actuando hacia el cambio, cuestionando las fuerzas sociales (solidaridad y acción) (Maguire, 1987).

\section{Sujetos del Estudio}

Desconocía la población total de mujeres puertorriqueñas que hacen uso de la medicina natural como alternativa para prevenir o curar sus problemas de salud y los de otras personas en su familia y su comunidad. Por otro lado, más que recopilar evidencia cuantitativa, me interesaba profundizar en la evidencia cualitativa existente sobre el tema al que hace referencia este estudio. Por tal razón, para este estudio no se me requería, ni menos aún, me interesaba ser fiel a procedimientos de determinación de población y selección de muestra probabilísticos. En su lugar, opté por un método de muestreo no probabilístico, una adaptación del procedimiento de «snowball».

Nueve mujeres fueron las sujetos del estudio. Estas son residentes de los pueblos o la ruralía de Cidra, Aibonito, Río Grande y Carolina. Establecí contacto con personas clave ligadas al trabajo en defensa del ambiente y la salud popular a través de entidades comunitarias y la propia comunidad.

Gracias a la colaboración de la organización de base comunitaria en defensa del ambiente, Despertar Cidreño, logré comunicación con seis yerberas, cuatro residentes en el casco del pueblo de Cidra y dos en el sector rural del mismo pueblo. A través de la misma organización inicié contactos para localizar a una de las parteras en Aibonito. Cuando me encontraba buscando a esa sujeto en el Hospital Menonita de Aibonito, me refirieron equivocadamente a una enfermera obstétrica. En la conversación informal que sostuve con ésta me informó que había asistido durante los últimos 37 años, a más de 3,000 partos de mujeres puertorriqueñas y añadió su preferencia por la integración de enfoques y métodos naturales en su práctica. Estos dos elementos me convencieron de lo valioso de su testimonio para los propósitos del estudio y contribuyeron a que 
la seleccionara como sujeto, lo cual ésta aceptó. Por otro lado, esta sujeto conocía a la partera que estaba tratando de localizar y me facilitó llegar a ella. A su vez, ésta trabaja en sociedad con la otra partera entrevistada. La última sujeto, una santiguadora del Barrio Cacao de Carolina fue referida a mí por su sobrina, quien laboraba en la unidad que trabajo y mostró interés por el estudio.

\section{Recopilación de Datos}

Como instrumento para la recopilación de datos utilicé una guía de preguntas a través de la cual recogí la información necesaria para explorar los propósitos del estudio. La misma constó de dos partes: datos sociodemográficos y especificaciones de la práctica.

El testimonio oral constituyó el método de recopilación de datos. Luego de compartir y obtener el consentimiento de las mujeres-sujetos sobre las particularidades del procedimiento, apliqué el mismo. Este consistió de conversatorios con cada una de las mujeres, en los que seguía las preguntas de la guía, la cual mantenía más como referencia que como instrumento de medición. Cada uno de los testimonios lo grabé en cinta magnetofónica y de cada una de las grabaciones preparé una transcripción «verbatim».

\section{Procedimientos de Análisis}

El análisis de los datos lo llevé a cabo por medio de un procedimiento esencialmente cualitativo. Primeramente, di lectura a cada una de las transcripciones, anoté ideas que se me iban ocurriendo al margen y subrayé aquellas que consideré importantes a la luz de los propósitos del estudio. Como segundo paso, siguiendo un método aleatorio, leí varios testimonios, tratando de descubrir los mensajes escondidos, subyacentes, sin prestar tanta atención a la información sustantiva. Una vez más anoté los pensamientos que surgían al margen.

El tercer paso consistió en preparar un listado de todos los tópicos. Agrupé los similares y los ubiqué en columnas. Estos pasaron a ser los tópicos principales del estudio. Anoté los tópicos individuales de cada mujer-sujeto y los sobrantes.

Como cuarto paso, asigné códigos a los tópicos. Regresé a los datos y anoté códigos en los segmentos de cada texto. Al llevar a cabo este paso, examiné nuevos tópicos y nuevos códigos. 
En el quinto paso convertí los tópicos en categorías. Tracé líneas entre las categorías lo que facilitó ilustrar sus interrelaciones. En el sexto paso asigné abreviaturas a las categorías y las coloqué en orden alfabético.

Organicé los datos relativos a cada categoría y realicé un análisis preliminar como parte del séptimo paso. No fue necesario recodificar los datos obtenidos.

Esencialmente llevé a cabo el procedimiento descrito por Creswe11 (1994). La cantidad voluminosa de información que recogí a través de las entrevistas las reduje identificando patrones o temas a los cuales asigné códigos. Interpreté dichos tópicos al utilizar un esquema de contextualización y recontextualización. Preparé un plan de matrices, tablas y semitabulares que muestra la relación entre los tópicos convertidos en categorías.

La consistencia entre el relato de las propias mujeres y las referencias que de ellas hacían otras personas de la comunidad contribuyó hacia la constatación de la confiabilidad del estudio. La consistencia entre los relatos de las mismas mujeres sobre su práctica, ofrecidos en distintos momentos del tiempo, abonó además a la confiabilidad de la investigación. A su vez, el alto grado de conformidad alcanzado entre lo que las mujeres narraron sobre su práctica y lo que la investigadora había obtenido de fuentes de información de la comunidad en referencia a los aciertos de sus prácticas, sirvió para medir la validez del estudio.

\section{Limitaciones del Estudio}

La localización de sujetos no fue algo muy fácil. Fui comunicando el mensaje a distintas personas y varias respondieron refiriéndome sanadoras. No obstante, en el pueblo de Cidra algunas de las sanadoras sugeridas ya habían participado en la investigación de Benedetti (1996). En lo respectivo a las parteras y santiguadoras me fue más difícil aún localizar sujetos.

La culminación de la investigación me tomó más tiempo del que hubiera previsto debido a que la realización de dicha tarea fue paralela a las restantes tareas de la docencia. 


\section{Hallazgos}

Atesoro profundamente cada una de las experiencias que las nueve mujeres entrevistadas me permitieron vivir al abrirme las puertas de sus hogares de la manera más desinteresada, incondicional y hospitalaria que pueda existir. Llegué a sus casas en la mayoría de los casos, sin previo aviso, como señalé anteriormente, luego de establecer contactos informales con varias personas que, a su vez, desinteresadamente, me sirvieron de eslabón y me facilitaron el primer encuentro con las mujeres, protagonistas de este estudio.

Procedo a presentar aspectos de la biografía social de las mujeres. En cuanto a sus edades todas las décadas desde los ' 30 hasta los '90 estuvieron representadas, siendo la más joven Debbie con 32 años y la mayor Ana con 99 años. Con relación a su escolaridad, también resultaron ser muy heterogéneas. Dos de las mujeres no asistieron nunca a la escuela. Otras dos cursaron hasta algún grado de escuela elemental. Dos contaban con algún grado del nivel intermedio, una de las cuales además poseía adiestramiento en enfermería práctica. Otra estudió enfermería obstétrica. Por último, dos cursaron adiestramiento en partería. Una de éstas, a su vez, estudió bachillerato universitario en educación. La otra realizó estudios en sicología, antropología, algunos a nivel de maestría. Ambas fueron adiestradas en emergencias médicas.

Cinco de las mujeres son yerberas. Una de éstas trabajó como enfermera práctica y cuidó personas de la tercera edad. Dos son parteras y una de éstas también educadora. Una es enfermera obstetra y una santiguadora. De las nueve mujeres, siete integran su oficio al de trabajadora doméstica.

Cinco de las mujeres residen en el área urbana y cuatro en el área rural. Seis de las mujeres son de religión católica, una menonita, otra budista y una creyente en un ser supremo. Solamente dos no practican su religión. Una de estas últimas señaló que integra la oración a su práctica curativa.

Cuatro de las mujeres están casadas legalmente, dos conviven consensualmente con sus compañeros, una es viuda y dos solteras.

Un total de seis mujeres poseen hijos(as) propios(as) o de crianza y tres no tienen hijos. La cantidad de hijos(as) varió desde uno(a) hasta catorce, tanto hembras como varones.

Cinco de las mujeres residen con familiares, dos con sus concubinos, una con su compañera de trabajo y una sola. 
Doña Juana utiliza las plantas medicinales con su familia. Por otro lado, prepara un jarabe a base de plantas que es muy solicitado por personas de su familia y de la comunidad. Al comentar sobre el jarabe dijo:

...porque esto yo lo sé de mi mamá porque antes, tú sabes, no habian do'tores, niña se curaba uno con las plantas...

Al ofrecer su testimonio sobre su práctica indicó:

...yo no uso muchas plantas a la vez. Yo me gusta usarlas aparte. Si porque asi se sabe para lo que sirve y para lo que no sirve. Ahora también de vez en cuando una liga'ita pa'ver cómo funcionan.

Debbie se identifica con «la partería y alguna yerba en específico». Esta dijo que practica la partería desde el 1991. Sobre cómo nació su interés en dicha área comentó:

Pues comenzó cuando una amiga mía iba a parir su bebé en el '84... pues segui estudiando, me gradué y luego tenía bien fuerte en la mente volver otra vez, tratar de irme a Estados Unidos a estudiar, porque allá dan los cursos y me dio un empuje y mucha inspiración otra colega que se fue a Estados Unidos a estudiar y así fue como comenzó todo.

Al referirse a las mujeres con quienes ha practicado, Debbie mencionó:

Pues, con todo tipo de mujer, de todas clases sociales y de todas las edades, mujeres jóvenes, mayores. Yo he trabajado aqui en Puerto Rico, en Texas donde estudié y también estuve en El Salvador trabajando.

Sobre cómo las mujeres conocen de sus servicios Debbie dijo:

Esto es por voces; se riega la voz, y me llaman, me consiguen y yo las atiendo.

Al referirse a la cantidad de partos que ha atendido, Debbie dijo:

He trabajado haciendo diversos trabajos en 71 partos...

Refiriéndose a la forma en que realiza su práctica, Debbie señaló: 
Pues cuando las mamás me llaman coordinamos una cita, o sea, que no hablo mucho por teléfono sobre la práctica, y entonces yo voy a la casa, cotejo su estilo de vida, cómo comen, cómo viven, le hago una entrevista como de dos horas, y si nos escogemos mutuamente, que ella me escoge a mi, yo la escojo a ella, que haga sus laboratorios, que llene mis requisitos, entonces comienzo el cuidado prenatal, atiendo el parto y el post-parto.

Sobre su función durante esta primera fase del embarazo Debbie mencionó:

Las oriento primeraménté en sus derechos como mujer embarazada y las responsabilidades de una mujer embarazada. Para í eso es vital para cualquier mujer, ya sea con su médico o conmigo misma. Y la dieta, enfatizo mucho en la dieta, la dieta es el punto clave para un buen parto en la casa. Las mujeres tenemos un 97 por ciento de que los partos salgan bien y la dieta es lo que juega un papel primordial. Además y en cuda rita colejo cómo ella la sigue. Además de eso cotejo sus semanas de gestación, su peso, todos los signos vitales, las medidas del abdomen, la posición del bebé, la orina; cotejo si puede tener señales de infección, si duerme bien, si hace ejercicios, todo un sinnumero de cosas en cada cita prenatal. Más que me traiga todos los laboratorios que se va haciendo continuamente con su médico, cotejar todos los laboratorios, eso es parte de los requisitos.

\section{Refiriéndose al parto, Debbie argumentó:}

Es importante dejar a la mujer sola durante el parto en ciertos momentos, el parto es un baile que ella es la que manda y uno es la que sigue, tú ves, que ella no se vaya en riesgo ni el bebé, esa es tu labor, pero ese es su parto y hay que respetárselo como tal y cuando ella puede sentirse libre de moverse como ella quiera y se toman las posiciones adecuadas para su cuerpo, ella segrega una serie de hormonas que la ayudan a mantener un buen parto y menos hemorragias y a sentirse bien y realizada en una transformación; para la partera, para la mamá y para las personas envueltas uno crece mucho, cada mamá.

\section{Debbie continuó explicando al referirse al parto:}

Yo soy una seguidora, ella es la líder, yo la sigo. Yo la ayudo, muchas a veces me llaman, muchas yo pues que, no me necesitan al lado tanto; ahora ya ellas saben mi trabajo, que las puedo interrumpir de vez en 
cuando, que yo tengo que ver que no haya riesgo ninguno y si hay una emergencia pues le digo necesito esta posición ahora. Ellas reaccionan siempre bien, pero durante el proceso, que a veces es largo y a veces es corto, yo tengo que bailar el ritmo de ella, no hay otra forma.

Al referirse a cómo la práctica de la partería le ayuda a ella como persona, Debbie señaló:

iAy! inmensamente, cada parto es un mundo aparte, aprendo desde... primero en el área de las ciencias, los laboratorios, siempre me siento y estudio aunque lo sepa lo leo de nuevo. Aprendo, me refresco la memoria. Como persona, en un parto, una mujer se transforma, pero una partera crece, uno crece muchísimo, me da much a sensibilidad, a veces como que uno entra en áreas de la conciencia de uno, le pasan cosas a uno que uno no sé...

Debbie mencionó cómo la partería ayuda a mejorar la autoestima de la mujer. Esta dijo:

...se siente autosuficiente, se siente que lo hizo bien y lo hace ella, para mi eso es el punto vital, porque desde chiquita nos están diciendo lo poco suficiente que somos las mujeres, como lo estábamos comentando, «la menstruación es un tiempo de debilidad y de enfermedad»; no; la menstruación es un tiempo de poder ser directa y decir lo que una siente. "El embarazo es un peligro»; no; es un tiempo de salud si se lleva bien y «la menopausia es el final", la menopausia es el tiempo de la sabiduría. Verdad, entonces como siempre nos quieren como echar a un lado, pues no. Cuando una mujer pare en su casa, la partera yo digo, no por mi pero por las parteras en general, siempre debe existir, porque me ayuda a mi autoestima y a la de la mujer. La mujer que está pariendo se siente bien, se siente fuerte, tiene poder, ella decide cosas, ella decide muchísimo. Cuando yo le digo mira te voy a hacer un examen, te puedo hacer un examen, "ahora no, ahora no, espérate un momentito porque me siento mal, tengo contracción, me quiero mover, quiero hacer esto, quiero ir al baño primero", todo lo que tú quieras, no hay ninguin problema, ella decide y yo la sigo. Ellas se sienten, se sienten usualmente bien cuando ellas ven que su cuerpo pare bien, que tiene esa habilidad, que ellas pueden lactar y dar alimento y darlo bien. Seguro que las eleva, que las hace sentir bien y eso es lo que buscamos, por lo menos yo, dentro de los objetivos eso es bien importante.

Al referirse a cómo la práctica de la partería la ayuda en su diario vivir, Debbie señaló: 
iAy! me ayuda porque me tengo que mantener estudiando y a mi me gusta, si, yo creo que voy a ser una eterna estudiante y me ayuda en mi diario vivir con la gente, me ayuda a concentrarme en la gente más, es que si no llega a ser por la partería como que no me enfocaría tanto, en tantos detalles y en tener más paciencia. Uno desarrolla una paciencia ante cualquier situación y a veces uno pierde la tabla y la pierde, la pierdo, y me pasa pero en situaciones de emergencia me siento que reacciono bien y eso me gusta, no me pongo nerviosa, trabajo, después me muero de los nervios y tiemblo como un tembleque, pero en el momento trabajo, eso me gusta.

Doña Ana Sosa Batista, al momento de la entrevista contaba con 99 años de edad. Se identifica a sí misma como santiguadora, práctica que aprendió de su abuela, quien a su vez, era comadrona.

Al preguntarle sobre cómo realiza su práctica dijo:

Bueno, el santiguo es una cosa de uno, tú sabes como ahora vamos a ver este, vamos a ponerle el nombre de una persona, pero a un niño, Juan, Rosa o lo que sea... Uno le dice: "Fulano, Juan te santiguo en nombre del Padre, del Hijo y del Espíritu Santo, Amén" (y se repite dos veces más). "Jesús en el nombre de Dios Padre, Jesús en el nombre de Dios Hijo, Jesús en el nombre del Espíritu Santo; como estas palabras son ciertas y verdaderas, en éstas quiero que ese cortado mal de alguien, mal de ojo o agua encharcado o cualquier otra cosa que tiene fulano de tal en su estómago o en su cuerpo que sea llevado al fondo del mar donde no le haga mal a nacientes ni a vivientes ni a cosas que Dios con su bendita mano haya creado. Santigua bendito te vengo a pedir, de toda enfermedad quiero subir, al todo bendito, te vengo a rogar con tanta enfermedad quiero sanar. Santa Ana parió a Maria y Santa Isabel a San Juan Bautista. Jesucristo murió, Jesucristo encarnó, Jesucristo resucitó viéndose la Virgen por aquel monte se encontró con su hijo y le dijo: "Señora te vengo a pedir con tanta enfermedad quiero salir, madre mía y señora con tu palabra y la mía, ¿̇cuál es la palabra: El Padre Nuestro y el Ave María? tierra de María. Este Padre Nuestro y esta Ave Maria que rezo para la salud de su gran Dios Santo Bernardo, que no le haga mal ni a naciente, ni a viviente, ni a cosas que Dios con su bendita mano haya creado. Ni con esto no basta, que baste con el nombre Dios Padre; ni con esto no basta, que baste con el nombre Dios Hijo; ni con esto no basta que baste con el nombre del Espiritu Santo ...Amén». Ahi se le reza un Credo al Santísimo frente al Cristo de la Salud.. y después se le prende una vela y pues la perso- 
na sale lo más bien; y si es una indigestión, pues se sabe, porque se va la indigestión del estómago donde la tiene.

Al preguntársele si cobraba por sus servicios doña Ana contestó que no, aunque mencionó que en ocasiones las personas voluntariamente le dejaban dinero con el cual ella le compra una vela al santo que intervino por esa persona.

Doña Ana explicó, a preguntas de la entrevistadora, que el santiguo se usa para las dolencias del cuerpo, no para condiciones nerviosas...

Doña Ana explicó que durante su práctica ella ora a Dios y a la Virgen y a los Santos, con lo que ayuda a las personas a mejorar su salud.

...Ajá, a mejorar su salud. Ahora de espiritus yo no tengo nada, soy católica... sí, voy a la iglesia, ahora Nilda me lleva a...

\section{Análisis de Hallazgos}

Hacedoras de bienestar, al servicio de su comunidad, cual abejas obreras protectoras de su abeja reina, trabajadoras incansables, defensoras de la Madre Naturaleza; así son las mujeres protagonistas de este estudio.

Estas nueve mujeres dieron rienda suelta a su verbo, compartiendo con nosotras su quehacer y concediéndonos el privilegio de documentar su obra. Procedo a presentar el producto del análisis individual y de conjunto que llevé a cabo.

Las yerberas tendieron a predominar cuantitativamente, siendo cinco de las nueve mujeres. Realmente todas integran el uso de yerbas a su práctica, ya que los testimonios de dos de las tres parteras y de la santiguadora evidencian la utilización de plantas medicinales.

Aprendieron su oficio de sus antepasados (principalmente de sus abuelas), a excepción de las parteras, quienes recibieron adiestramiento formal en escuelas de partería (2) o en una universidad. Este hallazgo demuestra que para que la medicina popular permanezca, es vital que se siembre la semilla entre los miembros de las generaciones más jóvenes.

Fue bastante la diversidad en cuanto al tiempo que llevan ejerciendo su práctica. Desde Doña Ana, nonagenaria que ha ejercido 
desde jovencita; Doña Juana que ha utilizado las yerbas por 40 años, hasta Debbie, partera desde hace cinco años y Fela, yerbera desde hace seis años. Resulta esperanzador que el saber popular de la tercera edad sea atractivo a personas más jóvenes al punto de interesarse por practicarlo. No obstante, en lo respectivo a las santiguadoras, resultó difícil localizarlas, presumo que por su escasez, lo cual las coloca en riesgo de desaparecer si no se logra que personas jóvenes aprendan el oficio.

Las mujeres del estudio se caracterizaron por el ejercicio de su práctica al servicio de su familia y la comunidad. Como indicó Tita en su testimonio al preguntarle con quién ejerce su práctica.

[con] el necesitado, no importa y a sea un familiar o sea una persona que yo no conozca que venga aquí..(Sujeto Núm. 3:33).

A través de sus testimonios las mujeres evidenciaron su alto nivel de compromiso con las personas en general. Su obra es prueba fehaciente de interés genuino por ayudar y en ninguna manera revela un fin lucrativo. En una sociedad donde el fin utilitario y económico se ha convertido en la norma, las mujeres-sujetos resultan ser la excepción. Son modelos dignos de emular y contribuyen significativamente a rescatar no sólo el lugar protagónico de la mujer en el campo de la salud comunitaria, sino valores de altruismo y compromiso social, tan apremiantes en el Puerto Rico de hoy.

Las yerberas tendieron a coincidir significativamente en las plantas identificadas y en el uso que le dan. A manera de ilustración, doña Juana, Felícita, Tita y Virginia coinciden en que el poleo es efectivo contra los malestares de estómago. El anamú es utilizado para combatir el cáncer por doña Juana, Felícita, Tita, Virginia y Esther. La juana blanca es utilizada para expulsar piedra del riñón por doña Juana, Felícita y Virginia. A la manzanilla le atribuyen poderes sedativos doña Juana, Felícita y Tita. La sábila es ingrediente esencial de los jarabes para combatir el catarro según doña Juana, Felícita, Tita, Esther y Virginia. Por su parte Felícita, Tita y Virginia identificaron la salvia para atacar la ronquera. Además coincidieron en el uso de rezos al aplicar la planta seleccionada, ya fuera por ejemplo, bendiciendo un té o rezando una oración al colocar una cataplasma.

El inventario de plantas utilizadas por las mujeres sobrepasa las cien y si a éstas se le suman las frutas, viandas y substancias minera- 
les a las que éstas le atribuyen propiedades medicinales, la cifra aumenta considerablemente. Esto denota la riqueza milenaria que se ha ido acumulando y trasmitiendo de generación en generación. No obstante lo significativo del hallazgo cuantitativo, lo verdaderamente sobresaliente es la dimensión cualitativa destacada en la convergencia entre un testimonio y otro en cuanto a las plantas y sus usos.

Las parteras, por su parte, contribuyen mediante su práctica a que la mujer rescate el lugar protagónico que ocupó en la antigüedad. La partera actúa como recurso central en el evento vital del ser humano, el nacimiento. Así, rescata el rol crucial de la mujer en la antigüedad como sanadora de la comunidad. La mujer que pare, sienta las bases para el apoderamiento de la mujer del proceso antes, durante y después del parto.

Como señalé anteriormente las santiguadoras van escaseando cada vez más. Y es a través de su práctica que la mujer logra establecer el vínculo entre la búsqueda de la salud y la espiritualidad.

Los testimonios de las nueves mujeres-sujetos de este estudio constituyen en sí mismos evidencia suficiente e incuestionable del aporte social que hacen a su comunidad. Cada una, a través de su práctica, contribuye a prevenir o curar los males que aquejan a nuestra población.

Las yerberas demostraron que existe una extensa gama de remedios para prevenir o curar las enfermedades del ser humano. A manera de ejemplo, algunas de las plantas mencionadas por las yerberas con sus correspondientes usos fueron: la hoja de aguacate para el dolor de cabeza (Felícita, Virginia); la altamisa (artemisa) aplicada en baños para resfriados (Juana, Felícita, Virginia); el anamú para el cáncer, (todas); el cundeamor para problemas de la piel (Felícita); la caña fístula (Felícita), el cohollo de calabaza y la hoja de apio (Juana) para la fatiga; la juana blanca para expulsar piedras de los riñones (Juana, Felícita, Virginia); el llantén para infecciones y para el cáncer (Juana, Felícita); la malva para infecciones vaginales (Juana, Felícita, Esther); el naranjo para calmar los nervios (Juana) y el moriviví para el dolor de muelas (Felícita).

Las parteras, por su parte, mencionaron una serie de plantas que utilizan a través de «las etapas del parto». El jengibre lo usan para estimular el parto; la ortiga para evitar hemorragias; la alfalfa para aumentar los niveles de hierro; las cataplasmas de yerbabuena para el útero que no evoluciona; la ruda para falsos partos y menstruaciones irregulares y la valeriana para calmar los nervios. 
La santiguadora utiliza primordialmente algún aceite para dar el sobo en la parte del cuerpo afectada. También utiliza teses de plantas como el poleo y el pazote para complementar el recurso principal del sobo.

Cada uno de los ejemplos antes presentados abona al ámbito social pues contribuye a propiciar estados óptimos de salud. En la medida en que una persona experimenta un estado óptimo de salud, puede ejecutar las funciones de su diario vivir con energía y entusiasmo, con eficiencia y creatividad. Así cuando doña Juana, Felícita o Tita le ofrecen la manzanilla a una persona para calmar sus nervios están contribuyendo a que dicha persona se relaje y pueda llevar a cabo sus funciones cotidianas. De igual manera, cuando Debbie o Rita utilizan el té de jengibre para estimularle el parto a una mujer están trabajando mano a mano con ella para lograr un parto natural (como se ha señalado antes, la labor de la partera se inicia en el período prenatal y se extiende al postparto). Finalmente, cuando doña Ana santigua mediante la combinación del sobo y los rezos, por ejemplo a un niño o a una niña que padece de «empacho» le transmite energía sanadora a través de sus manos y colabora en que pueda continuar ejerciendo su papel de niño o niña que juega, niño o niña que asiste a la escuela y otros.

Por otro lado, tanto la yerbera, la partera como la santiguadora aportan a preservar niveles óptimos de salud, al ofrecer alternativas más allá de la farmacopea. Contribuyen de esa manera, a evitar los efectos secundarios provocados por los elementos químicos presentes en los medicamentos.

El impacto económico para la persona que recurre a la sanadora natural por lo general es mucho menos elevado, si se compara con el costo de un tratamiento a través de la medicina alopática. Como se ha señalado anteriormente, la inmensa mayoría de las sanadoras operan gratuitamente y como la mayor parte de lo que utilizan para atender a la persona proviene directamente de la naturaleza o de las reservas físicas, mentales o emocionales de la persona o de ella misma, su costo económico es mínimo o ninguno.

Los remedios documentados por las sanadoras atienden desde un dolor de cabeza (manzanilla) hasta un dolor por piedra en el riñón (juana blanca). En otras palabras, las sanadoras prestan atención a síntomas, mas también a enfermedades o condiciones claramente definidas. 
Sobre todo, la aportación social más significativa de las sanadoras radica en el potencial preventivo de sus prácticas. Por un lado, muchas de las alternativas naturales que ellas les recomiendan a las personas, como señalé anteriormente, ayudan a prevenir que la dolencia se convierta en un mal mayor. Así es el caso del jarabe de sábila como componente primordial para ayudar a la persona a expectorar, evitando posibles complicaciones de una bronquitis o una pulmonía. De igual manera, ocurre con la juana blanca y la vaquiña como plantas que se utilizan para expulsar piedras de los riñones. Al lograr lo anterior, la persona no tiene que recurrir a intervención médica para extracción de la(s) piedra(s). En otras circunstancias, las alternativas naturales utilizadas por las sanadoras aportan totalmente a la prevención primaria. Éste es el caso de lo que logran las parteras en la inmensa mayoría de sus intervenciones. Desde la etapa prenatal, la partera va sentando las bases hacia un parto natural. Mediante la educación, la integración de una dieta adecuada, el ejercicio y la modificación de actitudes, la partera socializa a la parturienta para que internalice que ella posee todo el derecho de apoderarse del proceso, actuar como sujeto y dejar fluir su energía interna de forma natural.

Desde el interior de su práctica las sanadoras aportan a que las personas se mantengan ejecutando sus roles sociales, gozando de una salud óptima tal como la define Weil con «fortaleza interior que [aunque] la persona esté en contacto con peligros o riesgos al organismo, no contrae la enfermedad» (Weil, 1998:88).

Un hallazgo sumamente significativo es que, de acuerdo con las sanadoras, el estado de salud de ellas y de sus familiares es satisfactorio, óptimo en la mayoría de los casos. No podemos generalizar, mas sería pertinente llevar a cabo estudios posteriores que pudieran investigar la posible relación entre el uso de alternativas de salud natural por mujeres puertorriqueñas y el estado de salud de éstas y sus familiares. Se advierten posibles relaciones entre dichas prácticas y estados sanos de salud, en otras palabras se advierten estas prácticas como medios que promueven la salud. 


\section{Conclusiones}

Damos las gracias primeramente a nuestra madre, la tierra, que nos sostiene, después a los ríos y corrientes, a las hierbas, al maiz, las habichuelas y los calabacines, a los arbustos y los árboles, al viento, a la luna y las estrellas, al sol y finalmente al Gran Espiritu que dirige todas las cosas.

Indios Iroquois

El haber podido recoger el testimonio de las mujeres participantes de este estudio ciertamente fue un privilegio. Mi interés por estudiar áreas de tangencia entre lo social y las prácticas de salud me llevó a descubrir la integración particular que cada una de las mujeres-sujetos ha hecho de su práctica a su diario vivir. En cada una el aporte social emana espontáneamente a través de su quehacer.

Quedó demostrado, mediante los testimonios, cómo las mujeres-sujetos mediante su práctica contribuyen a prevenir o curar los males que aquejan a nuestra población.

Quedó demostrado, mediante los testimonios, cómo las mujeres-sujetos aportan al ámbito social propiciando con su práctica estados satisfactorios u óptimos de salud, los cuales, a su vez, permiten que las personas realicen eficientemente las funciones de la vida cotidiana.

Quedó demostrado, mediante los testimonios, que la aportación más significativa de sus prácticas es cómo éstas ayudan a prevenir enfermedades.

No obstante la reducida cantidad de sanadoras entrevistadas, la diversidad predominó en lo concerniente a características sociodemográficas. Mujeres con edades desde los '30 hasta los ' 90 ; unas que nunca han ido a la escuela y otras que han cursado estudios graduados; residentes de la ruralía unas y otras de áreas urbanas; algunas católicas, una protestante, otra budista; unas casadas legalmente, otras conviviendo consensualmente con sus cónyuges; unas casadas, una viuda, otras solteras; unas con hijos propios o de crianza, otras sin hijos; unas con un solo hijo otras con más, hasta 14 y, finalmente, unas que residen con su pareja, otra con familiares o amigos y una sola.

El estado de salud de las sanadoras y de sus familias es satisfactorio u óptimo, según revelan sus testimonios. Queda por investigarse la posible relación entre este hallazgo y la utilización de prácticas de salud natural. 
Quedó demostrado que para realizar sus prácticas las sanadoras utilizan plantas y otros recursos producto de la naturaleza.

La investigación me llevó a reflexionar como persona y trabajadora social sobre lo importante que es para la profesión ganar comprensión de las personas y su cotidianidad. En el estudio aprendí a valorar aún más las sanadoras y la contribución social que hacen por medio de su quehacer.

\section{Recomendaciones}

Al llegar a la etapa final de la investigación presenté las siguientes recomendaciones:

1. Que se continúen abordando aspectos de la realidad social que aparentemente no guardan tanta relación con el trabajo social, mas que al hacer un análisis más profundo, se descubre que abonan significativamente a las dimensiones de conocimiento, valor y método de la profesión.

2. Que se continúe promoviendo la investigación cualitativa en trabajo social sobre temáticas que arrojen luz en torno a la pertinencia del mundo humanístico para la profesión.

3. Que se continúen fomentando investigaciones sobre otros sectores humanos de manera que éstas puedan redundar en intervenciones de trabajo social mas efectivas.

4. Que se promuevan futuras investigaciones sobre la posible interrelación entre la utilización de alternativas de salud natural y estados sanos de salud.

\section{Bibliografía}

Alexander, A. (1998). Ask Dr. Weil. Prevention, 50(1): 86-93.

Arrieta Vilá, R. (2000, 15 de septiembre). De Todo un Poco. El Nuevo Día. 143. Guaynabo, Puerto Rico. 
Arrieta Vilá, R. (2000, 14 de septiembre). De Todo un Poco. El Nuevo Día. 145. Guaynabo, Puerto Rico.

Association of Radical Midwives (2000). What is a Midwife? Disponible en Internet. www.radmid.demon.co.uk/whatis.htm.

Benedetti, M. (noviembre, 1997). iBendiciones Botánicas! Vela Encendida, (6):15.

Benedetti, M. (1996). Sembrando y sanando en Puerto Rico. Mayagüez: Verde Luz.

Benedetti, M. (1992). îHasta los baños te curan!: Remedios caseros y mucho más de PuertoRico. Saline: McNaughton and Gunn, Inc.

Berry, T. (1988). The dream of the earth. San Francisco: Sierra Club Books.

Carlson, R.J. (1975). The end of medicine. New York: John Wiley and Sons.

Collinge, W. (1996). The American Holistic Health Association complete guide to alternativemedicine. New York: Warner Books, Inc.

Creswell, J.W. (1994). Research design: Qualitative and quantitative approaches. Thousand Oaks: Sage Publications.

Delgado, M. (1979). Herbal Medicine in the Puerto Rican Community. Health and Social Work. 4(2): 25-40.

Delgado, M. (1978). Folk Medicine in the Puerto Rican Culture. International Social Work. 21(1): 46-54.

Durán, M.A. (1983). Desigualdad social y enfermedad. Madrid: Editorial Tecnos.

Farnsworth, N.R. y otros (1989). Bol of Saint Panam 107(4): 314-329.

Green, M. (1989). Signs. Winter. 434-473. 
Grieve, M. (1971). A modern herbal; the medicinal, culinary, cosmetic and economic properties, cultivation and folklore of herbs, grasses, fungi, shrubs and trees with all their modern scientific uses. New York: Dover Publications.

Instantáneas (1991). Bol of Saint Panam. 111(2).

Liogier, H.A. (1990). Plantas medicinales de Puerto Rico y del Caribe. Segunda Edición. San Juan: Iberoamericana de Ediciones.

López Díaz, R. (1995). La Religiosidad de las Curanderas en Puerto Rico. Monografía presentada en el curso Teol. 582-Religiosidad Popular. Bayamón: CEDOC.

Maguire, P. (1987). Doing Participatory Research: A Feminist Approach. Boston: The Center for International Education. University of Massachusetts.

Northrup, C. (1994). Women's bodies, women's wisdom: creating physical and emotional health and healing. New York: Bantam Books.

Null, G. (1992). Healing your body naturally: Alternative treatments to illness. New York: Four

Walls Eight Windows.

Robiou Lamarache, S. (enero 1996). Plantas Medicinales Taínas. La Era de Ahora: 5.

Rodríguez Malavé, E. (1999). Medicina natural: Retorno a nuestra esencia. Río Piedras:Editorial de la Universidad de Puerto Rico.

Stein, D. (1999). Todas las mujeres somos sanadoras: Guía práctica de sanación natural. Madrid: Arkano Books.

Stein, D. (1992). Mujeres que curan. Barcelona: Ediciones Martínez Roca, S.A.

Taylor, J.B. (1993). «The Naturalistic Research Approach» en Grinnell, R. Social work research and evaluation. Itasca: F.E. Peacock Publishers, Inc. 
Temas de Actualidad: La medicina tradicional. (1990). Bol of Saint Panam. 108(1).

Vox: Diccionario Actual de la Lengua Española. (1996). NTC Publishing Group: Chicago.

Wellness made easy: 365 tips for better health. (1995). Berkeley: University of California. 